Article

\title{
Escape from Working Poverty: Steps toward Sustainable Livelihood
}

\author{
Jarrod Haar ${ }^{1, *(D)}$, Stuart C. Carr ${ }^{2}$, James Arrowsmith ${ }^{3}{ }^{-}$, Jane Parker ${ }^{3}$, Darrin Hodgetts ${ }^{2}$ and \\ Siautu Alefaio-Tugia ${ }^{2}$ \\ 1 New Zealand Work Research Institute, Department of Management, Auckland University of technology, \\ Auckland 1142, New Zealand \\ 2 Project GLOW (Global Living Organisational Wage, http:/ / www.massey.ac.nz/project-glow), End Poverty \\ \& Inequality Cluster (EPIC), School of Psychology, Massey University, Auckland 1142, New Zealand; \\ S.C.Carr@massey.ac.nz (S.C.C.); D.J.Hodgetts@massey.ac.nz (D.H.); S.Alefaio@massey.ac.nz (S.A.-T.) \\ 3 Co-Director MPOWER, School of Management, Massey University, Auckland 1142, New Zealand; \\ J.Parker@massey.ac.nz (J.P.); J.Arrowsmith@massey.ac.nz (J.A.) \\ * Correspondence: jarrod.haar@aut.ac.nz
}

Received: 10 October 2018; Accepted: 5 November 2018; Published: 11 November 2018

\begin{abstract}
Working poverty affects over half the world's working population, yet we know remarkably little about the role of wages in transitioning toward sustainable livelihood. We develop and test a model whereby as pay approaches a living wage range, pay fairness becomes clearly associated with work-life balance; this in turn links to job satisfaction, which is a four-step process at the psychological level. We further extend this by testing a moderated mediated model, whereby income level is tested as a boundary condition. Using data from $N=873 \mathrm{New}$ Zealand employees, we focus on relatively low-waged employees across three levels of income: up to $\$ 20,000, \$ 20-40,000$, and $\$ 40-60,000$, with the last band straddling the New Zealand Living Wage. We find strong support for pay fairness predicting work-life balance and job satisfaction, with work-life balance mediating the relationship toward job satisfaction. In addition, we find direct effects from income to work-life balance, although not job satisfaction. Furthermore, two-way moderation is supported toward work-life balance and job satisfaction, with higher income employees reporting higher outcomes when fairness is high. The index of moderated mediation is also significantly supporting, indicating that work-life balance has a stronger mediation effect as income rises. Thus, as workers emerged from working poverty, pay fairness, and in turn work-life balance, became psychologically more salient for happiness at work, implying that a pathway to Sustainable Development Goal 8 includes at least three psychological steps, in addition to the pecuniary issue of pay: fairness, work-life balance, and job satisfaction.
\end{abstract}

Keywords: working poverty; SDGs; pay fairness; work-life balance; job satisfaction; moderated mediation

\section{Introduction}

We understand little about the psychology of working poverty [1], including the psychology of transitioning from it toward more sustainable livelihoods [2]. In particular, linkages between "employee pay and human thriving remain theoretically and empirically under-explored at the lower-end of the wage-and-income spectrum" [2] (p. 215). Compounding this gap in our understanding is an under-representation of countries outside of the United States [3]. In their meta-analysis of pay level and job satisfaction, Judge et al. [4] acknowledged that the United States (US) is arguably the wealthiest if one of the most unequal developed countries on earth, and that studies set within the US are likely to be relatively unique within a pay context. Nevertheless, $84 \%$ of the studies in their meta-analysis that were focused on, "How does the pay we receive from our work contribute to our feelings about our jobs and 
lives?" [4] (p. 157), were based in the US [4]. The present study seeks to answer the same question, but in the context of the working poor in New Zealand. Importantly, we seek to understand whether at the lowest levels of pay, are there differences in the way that pay fairness influences job satisfaction for the working poor. Other meta-analyses beyond Judge et al., for example [5], have shown that pay can play an important role in shaping job attitudes and behaviors, although seldom in the context of working poverty [2].

Within the broad changes occurring globally, Di Fabio [6] noted that growing job insecurity means that employee well-being has been put at risk [7], but this also provides research opportunities that are accordingly arising for a new area of research around the psychology of sustainability [6]. The focus on the psychology of sustainability refers to the quality of employee life [6], and this aligns well with the present study's focus on working poverty. What mechanism and relationships differ within the working poor 'cohort', and are there benefits to earning more income toward enhancing one's life? Are these effects subtle, such that a small increase in income is effective? Di Fabio [8] noted that, "work plays a key role in the health and well-being of workers" (p. 1), and we suggest this may be especially true for lower paid workers in general.

Greenberg [9] noted that organizational justice refers to employee perceptions of fairness within their organizations, and typically in relation to compensation [10]. For example, fairness perceptions can encompass reactions to the amount of compensation received, with more favorable reactions leading to higher job satisfaction [10]. However, we do not know well whether workers earning barely enough money to survive might hold similar effects from pay under organizational justice theory. Thus, understanding how these perceptions around pay fairness might influence job satisfaction - which is an important component of well-being [2,6], and a prime determinant of job performance [11]—is important to explore.

The present study makes contributions based on examining pay fairness and job satisfaction amongst the working poor, and tests income level as a moderator of relationships. In addition, it builds on emerging research showing the importance of work-life balance as a mediator of relationships [12,13], and extends these relationships by testing a moderated mediated relationship, to explore the influence of pay fairness within the boundary conditions of pay levels. Overall, the paper makes significant inroads into showing that organizational justice theories hold, even for the working poor, but that there may be boundary conditions under which relationships are stronger for higher paid employees. Our study model is shown in Figure 1.

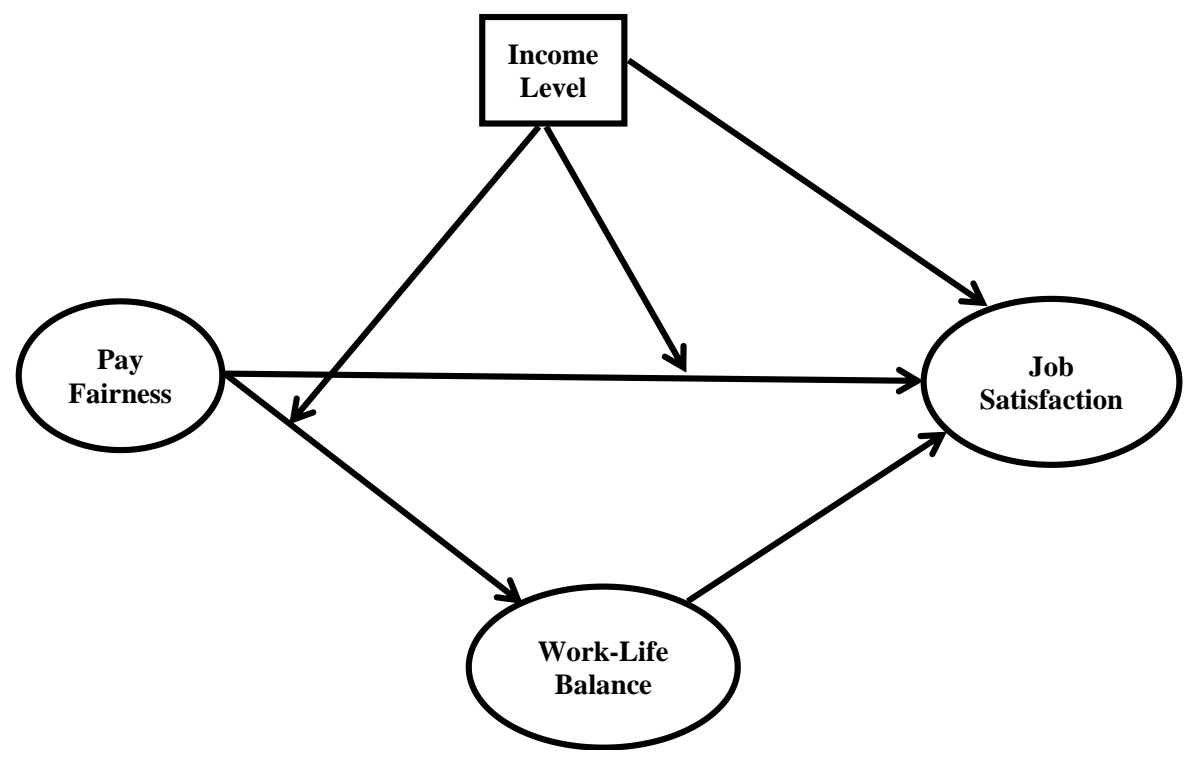

Figure 1. Study Model. 


\subsection{Pay Fairness}

Cropanzano et al. [14] stated that, "Organizational justice-members' sense of the moral propriety of how they are treated-is the 'glue' that allows people to work together effectively. Justice defines the very essence of individuals' relationship to employers" (p. 34). Rupp et al. [15] stated that, "Organizational justice has been identified as one of the more dominant and frequently studied topics in industrial-organizational psychology, organizational behavior, and human resource management" (p. 919). Despite this broad support, there is an acknowledgement that the psychology field understands less about those at the bottom of the pay spectrum, for example [2]. Carr et al. [16] noted that, "Work may be a panacea for poverty, but the world of work in 2018 is characterized by 'Working Poverty'" (p. 901), reinforcing the point that our understanding of workers in low paying jobs is poor. We focus on pay fairness amongst the lowest paid workers of New Zealand, because this is the most appropriate form of organizational justice to examine, and this approach addresses gaps in our understanding.

Early organizational justice research, for example [17], focused on fairness perceptions around the distribution of rewards (distributive justice), which then expanded into procedural justice, for example [18], and interactional justice, for example [19]. Masterson et al. [20] stated that there is "substantial evidence that fairness is an important dimension affecting employees' actions and reactions within organizations" (p. 738). In their meta-analysis, Colquitt et al. [21] found that organizational justice was positively related to many outcomes, from job satisfaction and organizational commitment, to trust and organizational citizenship behaviors, accounting for $45 \%$ of the unique variance toward job satisfaction. These effects are similar to the meta-analysis results of Cohen-Charash and Spector [22], who found strong relationships between organizational justice dimensions and job satisfaction. Overall, aligned with the meta-analytic findings, we expect perceptions of fair pay to be related to job satisfaction.

Hypothesis 1. Pay fairness will be related to job satisfaction.

\subsection{Work-Life Balance}

Haar [23] proposed role balance theory for understanding work-life balance, stating, "attaining a level of self-perceived balance between these roles ... will enable employees to attain additional benefits from their roles through the successful management of these roles" (p. 3308). Various theoretical approaches to work-life balance have embraced a person-centric approach [23,24], where the key understanding of work-life balance comes from an employee's own perception of their ability to manage various life roles, including work and non-work roles [13,23]. Haar [23] defined work-life balance not assuming a division "in time, engagement, and satisfaction ... but [as] a personal assessment of how employees balance multiple roles" (p. 3308). Consequently, employees formulate a subjective appraisal of non-work and work roles, and thus, work-life balance represents the equilibrium and harmony between all of the roles that are perceived as being important to an employee.

Studies of work-life balance antecedents are rare beyond the work and family factors of conflict [14] and enrichment [23]. For example, Russo et al. [24] found workplace support to be a consistent predictor of work-life balance, and Haar, Sune, et al [25] found supervisor support and job autonomy was significantly related to work-life balance. While no study has examined the relationship between organizational justice and work-life balance, Judge and Colquitt [26] found that organizational justice was negatively related to work-family conflict, with feelings of justice reducing issues of work crossing over into the home domain. Thus, there is theoretical and empirical support for the proposition that fairness perceptions can influence the management of work and non-work roles. Studies by Haar et al. and Haar $[13,23]$ found that work-life balance mediated the influence of work-family conflict, and thus, we expect pay fairness to similarly shape work-life balance. Specifically, perceptions of fair pay might help employees focus on managing and balancing their multiple roles, because fairer perceptions means less worry about work (specifically pay), and enables 
employees to focus on harmonizing their multiple roles. This leads to our next hypothesis, where we posit that greater pay fairness will directly influence work-life balance.

Hypothesis 2. Pay fairness will be related to work-life balance.

\subsection{The Mediating Effect of Work-Life Balance}

There is clear evidence that work-life balance might best be viewed as a mediator of work and non-work factors on outcomes including job satisfaction. Haar [23] found that work-life balance mediated the influence of work-family conflict and enrichment, and this was replicated in seven samples across six countries regarding work-family conflict [13]. In a study of ethical leadership and leader-member exchange, Haar, Roche and Brougham [12] found that work-life balance fully mediated their effects toward job satisfaction. Similarly, a study of servant leadership on work engagement found that it was fully mediated by work-life balance [27]. Brough, Timms, et al. [28] found that work demands were negatively related to job satisfaction (cross-sectionally and longitudinally), but this effect was fully mediated by work-life balance. As such, there appears to be strong support for work-life balance as mediating the effects of work constructs, and we suggest that such effects will hold toward the influence of pay fairness on job satisfaction. Thus, we posit the following.

Hypothesis 3. Work-life balance will mediate the influence of pay fairness on job satisfaction.

\subsection{Income Level as a Moderator}

Carr et al. [2] argued that a decent wage is important to the thriving of employees and is likely to play an important role in enhancing job satisfaction. Recent research has shown that there can be changes in lower income ranges $[2,16,29]$, and thus, it might be overstating the theoretical pull of organizational justice around pay fairness to influence job satisfaction. It might be that those with the lowest pay are more likely to be thankful for any work, and thus register higher job satisfaction. Kim [30] noted that working poor are more likely to have "jobs that fail to provide full-year or full-time work, or jobs that pay wages that are too low" (p. 65). However, Kim [30] found that even working poor who worked around 40 hours a week for 52 weeks a year were still poor. US population data analyzed by Kalleberg et al. [31] found that 'bad jobs' - those with low pay and no benefits-included about one in seven jobs, and were related to poorer quality work. McGovern et al. [32] found similar effects in the United Kingdom, stating that jobs with lower pay were associated with more bad job characteristics.

Consequently, we consider it unlikely that those earning the least money from their work are likely to report stronger perceptions toward job satisfaction regarding pay fairness. Meta-analyses by Williams et al. [33] highlighted the importance of pay and pay satisfaction toward work outcomes, and this aligns with Griffeth et al. [5] around the importance of pay and turnover. In the present study, we argue that increases in pay level is likely to attenuate and enhance the positive influence of pay fairness perceptions on work-life balance and job satisfaction. Thus, a higher income level will moderate the relationships, with the highest work-life balance and job satisfaction reported for those with high pay levels and high pay fairness perceptions. Thus, we posit the following.

Hypothesis 4. Income level will moderate the influence of pay fairness on (a) work-life balance and (b) job satisfaction.

\subsection{Income Level as a Boundary Condition}

The present study tests the potential indirect effect of income level as a moderator (Hypothesis 4 above), but then also as a moderator on the mediated relationship between pay fairness on job satisfaction through work-life balance. As noted earlier, income level is seldom explored in employee studies, including those on pay fairness. We suggest that income level is likely to play an important role and act as a boundary condition, whereby the relationships among pay fairness-work-life balance-job 
satisfaction can be better understood via income level. Hayes [34] noted that while empirical studies in the behavioral sciences often test mediation and moderation effects, these analytic approaches can be combined into moderated mediation. The approach of moderated mediation is called conditional process modeling, which is defined as "an analytical strategy focused on quantifying the boundary conditions of mechanisms and testing hypotheses about the contingent nature of processes, meaning whether 'mediation is moderated'" [35] (p. 2). The value in conducting conditional process modeling is that it analytically addresses "whether an indirect effect (mediation) is dependent on another variable (moderation)" [35] (p. 2). We suggest given the focus on working poor in the present study, the exploration of income level as a boundary condition is worth exploring.

In their meta-analysis of pay satisfaction, Williams et al. [33] noted the importance of moderators on relationships, finding moderators around organizational justice dimensions. In their meta-analysis on pay level and job satisfaction, Judge et al. [4] reported a small but significant effect from pay level intervals on job satisfaction (estimated true score correlation $=0.17$ ). In their meta-analysis toward turnover, Griffeth et al. [5] found a small direct effect from pay, but also found that pay acted as a moderator, encouraging the use of pay within moderator analyses. Importantly, we know very little about the influence of pay level on job satisfaction for the working poor. It might be that employees struggling to earn sufficient income in 'bad jobs', for example [30,31], find very little influence of income on job satisfaction. They may consider their work is simply 'a job', and thus pay level has no influence on job satisfaction. Within the context of pay fairness and our outcomes (work-life balance and job satisfaction), we posit a moderated mediation hypothesis, suggesting that the strength of the influence of work-life balance as a mediator of the influence of pay fairness on job satisfaction will be a boundary condition of pay level (as the moderator). Thus, we posit the following.

Hypothesis 5. The indirect relationship between pay fairness and job satisfaction via work-life balance will be moderated by income level, such that the indirect relationship becomes stronger as income level raises (moderated mediation).

\section{Methods}

\subsection{Participants and Sample}

In 2017, a Qualtrics survey panel of New Zealand employees was undertaken of lower-paid employees, which resulted in 873 participants recruited who held a single job. We focused on perceptions of pay fairness and job satisfaction from a single job to minimize confusion if the employees worked multiple jobs. There was a filter question that confirmed the income of the respondent, with those reporting more than NZ $\$ 60,000$ automatically filtered out. We focused on three income groups: up to $\$ 20,000, \$ 20-40,000$, and $\$ 40-60,000$, with the latter including the New Zealand median wage of around $\$ 50,000$ [36]. Within Qualtrics panels, all of the participants are assured confidentiality, and they are anonymous to the researchers. Qualtrics pays respondents for their time, but the nature of this arrangement is proprietary. Thus, this is a paid respondent panel, although we suggest that this was required to target this low-paid worker cohort. The Qualtrics system has an estimated time for the survey (10 minutes in this example), and removes respondents who complete the survey too quickly or too slowly. It also assures that one respondent only can complete the survey. This approach to data collection has grown and provided useful samples for researchers [37-39]. We utilized this approach specifically because Qualtrics can target income-level within their respondent recruitment. This project has ethical approval (reference: NOR 18/04, title: "Living wages: Transforming lives, transforming work?").

Overall, respondents were more likely to be female (69\%), with age ranging from the early $20 \mathrm{~s}$ to over 60 years. The average age category was in the 30-35 age range. Hours worked ranged from 10 to $50+$ hours, with the average in the $26-30 \mathrm{~h}$ per week category. By ethnicity, $61 \%$ were New Zealand European, with the remaining 38\% of ethnicities being Maori (11\%), Asian (11\%), Indian 
(7\%), and Pacific peoples (6\%), with 3\% other. At the firm level, $67.8 \%$ were of respondents were from the private sector, followed by $18.1 \%$ from the public sector, and $14.1 \%$ from the not-for-profit sector. By firm size, respondents worked in a range of firms, with the majority $(27.7 \%)$ working in microsized firms (one to 10 employees), with the average being in firms with 50 employees. The remaining segment of respondents worked in larger firms, including those with more than 5000 employees $(8.6 \%)$. By income level, the majority (39.4\%) came from the $\$ 40,001-60,000$ band, closely followed by the $\$ 20,001-40,000$ band $(35.9 \%)$, and then the up to $\$ 20,000$ band $(24.7 \%)$.

\subsection{Measures}

Pay Fairness was measured using the three-item construct by Carr et al. [2], which was coded $-1=$ no, 0 = don't know, 1 = yes. Items followed the stem, "Do you think your wage is a 'fair rate'?", and a sample item is "compared to the line supervisors in your organization". The measure has been found to have good reliability [2,16], and had very good reliability in the present study $(\alpha=0.83)$.

Work-Life Balance was measured using the three-item measure by Haar [23], which was coded $1=$ strongly disagree, 5 = strongly agree. A sample item is: "Nowadays, I seem to enjoy every part of my life equally well". This construct has been well validated [12,25,27], including internationally [13], as well as in daily diary studies [40], showing it to be a valid and useful construct for tapping work-life balance. The measure had very good reliability in the present study $(\alpha=0.88)$.

Job Satisfaction was measured using three items of the construct used by Judge et al. [41], which was coded $1=$ strongly disagree, through to $5=$ strongly agree. A sample item includes, "I feel fairly satisfied with my job". This measure has been validated in New Zealand samples $[13,23]$. The measure had excellent reliability in the present study $(\alpha=0.91)$.

Income Level was determined by asking, "What income band is your individual annual income before tax?", and was coded $1=$ up to $\$ 20,000$ per annum, $2=\$ 20,001$ to $\$ 40,000$ per annum, and $3=\$ 40,001$ to $\$ 60,000$ per annum.

We controlled for factors typical of the literatures, for example [12,13,23,25,27]: Age $(1=$ less than 20 years, $2=20-25$ years, $3=26-30$ years, $4=31-35$ years, $5=36-45$ years, $6=46-55$ years, $7=56-65$ years, and $8=65$ years and over), because in their meta-analysis, $\mathrm{Ng}$ and Feldman [42] found that older workers were more positive about their job satisfaction. Hours Worked $(1=$ a minimum of $10 \mathrm{~h}$ /week, and then every number above that includes one to five more hours, thus $2=11-15 \mathrm{~h}$, $3=16-20 \mathrm{~h}$, etc. The highest is $14=71+\mathrm{h} /$ week) was controlled for because there is meta-analytic support [43] between long hours worked and more positive occupational outcomes. Finally, we control for Ethnicity $(1=$ New Zealand European, and $0=$ all other minorities $)$, because Statistics New Zealand [36] reported that New Zealand Europeans, the majority ethnicity, are significantly higher paid than other minority ethnicities.

\subsection{Analysis}

Hypotheses were tested using PROCESS version 3.1 (in SPSS version 25) as per Hayes [35], at the $95 \%$ confidence interval and bootstrapping at 5000 . We use multiple models to determine effects: model 4 for mediation effects, and model 7 (moderated mediation) to provide an index of moderated mediation, which is a statistical test for determining moderated mediation effects. We report Lower Limit Confidence Intervals (LLCL) and Upper Limit Confidence Intervals (ULCL).

\subsection{Measurement Model}

Using AMOS version 25, we conducted a confirmatory factor analysis (CFA) on our constructs, with guidelines from Williams et al. [44] regarding assessing model fit: (1) the comparative fit index (CFI $\geq 0.95$ ), (2) the root mean square error of approximation (RMSEA $\leq 0.08$ ), and (3) the standardized root mean residual (SRMR $\leq 0.10$ ). The hypothesized measurement model and three alternative models are shown in Table 1. 
Table 1. Results of Confirmatory Factor Analysis (CFA). CFI: comparative fit index, RMSEA: root mean square error of approximation, SRMR: standardized root mean residual.

\begin{tabular}{cccccccccc}
\hline \multirow{2}{*}{ Model } & \multicolumn{4}{c}{ Model Fit Indices } & \multicolumn{5}{c}{ Model Differences } \\
\cline { 2 - 10 } & $\boldsymbol{\chi}^{\mathbf{2}}$ & df & CFI & RMSEA & SRMR & $\boldsymbol{\Delta} \boldsymbol{\chi}^{\mathbf{2}}$ & $\boldsymbol{\Delta d f}$ & $\boldsymbol{p}$ & Details \\
\hline Model 1 & 82.6 & 24 & 0.987 & 0.053 & 0.033 & & & & \\
Model 2 & 876.8 & 26 & 0.808 & 0.194 & 0.096 & 794.2 & 2 & 0.001 & Model 1 to 2 \\
Model 3 & 886.3 & 26 & 0.806 & 0.195 & 0.137 & 803.7 & 2 & 0.001 & Model 1 to 3 \\
Model 4 & 876.4 & 26 & 0.808 & 0.194 & 0.135 & 793.8 & 2 & 0.001 & Model 1 to 3 \\
\hline
\end{tabular}

Model 1 = Hypothesized three-factor model: pay fairness, work-life balance, and job satisfaction. Model $2=$ Alternative two-factor model: pay fairness, work-life balance, and job satisfaction combined. Model $3=$ Alternative two-factor model: pay fairness and work-life balance combined, and job satisfaction. Model $4=$ Alternative two-factor model: pay fairness and job satisfaction combined, and work-life balance.

Overall, the hypothesized measurement model was the best fit for the data, with alternative measurement constructs resulting in a poorer fit [45]. The hypothesized measurement model was an excellent fit for the data: $\chi^{2}(24)=82.6(p=0.000)$, CFI $=0.987$, RMSEA $=0.053$, and SRMR $=0.033$. Alternative CFAs were found to be poorer fits $($ all $<0.001)$.

\section{Results}

Descriptive statistics for the study variables are shown in Table 2.

Table 2. Correlations and Descriptive Statistics of Study Variables.

\begin{tabular}{lcccccccc}
\hline \multicolumn{1}{c}{ Variables } & M & SD & $\mathbf{1}$ & $\mathbf{2}$ & $\mathbf{3}$ & $\mathbf{4}$ & $\mathbf{5}$ & $\mathbf{6}$ \\
\hline 1. Age & 5.6 & 2.0 & - & & & & & \\
2. Hours Worked & 5.5 & 2.5 & -0.02 & - & & & & \\
3. Income Level & 2.2 & 0.79 & $0.15^{* *}$ & $0.59^{* *}$ & - & & & \\
4. Pay Fairness & 0.23 & 1.0 & $-0.11^{* *}$ & $-0.14^{* *}$ & $-0.09^{*}$ & - & & \\
5. Work-Life & 3.4 & 0.90 & $0.11^{* *}$ & $-0.11^{* *}$ & 0.02 & $0.26^{* *}$ & - & \\
Balance & 3.6 & 0.96 & $0.18^{* *}$ & 0.03 & $0.08^{*}$ & $0.29^{* *}$ & $0.56^{* *}$ & - \\
6. Job Satisfaction & \multicolumn{10}{c}{$N=873^{*} p<0.05,{ }^{* *} p<0.01}$. & & &
\end{tabular}

Table 2 shows that pay fairness is significantly correlated with job satisfaction $(\mathrm{r}=0.29, p<0.01)$, work-life balance $(\mathrm{r}=0.26, p<0.01)$, income $(\mathrm{r}=-0.09, p<0.05)$, hours worked $(\mathrm{r}=-0.14, p<0.01)$, and age $(\mathrm{r}=-0.11, p<0.01)$. Work-life balance is significantly correlated with age $(\mathrm{r}=0.11, p<0.01)$ and hours worked ( $\mathrm{r}=-0.11, p<0.05)$, but not income $(\mathrm{r}=0.02$, non-significant). Job satisfaction is significantly correlated with age $(\mathrm{r}=0.18, p<0.01)$, income $(\mathrm{r}=0.08, p<0.05)$, and work-life balance $(r=0.29, p<0.01)$, but not hours worked $(r=0.03$, non-significant).

Results of the direct, mediation, moderation, and moderated moderated regression analysis toward job satisfaction are presented in Figure 2. 


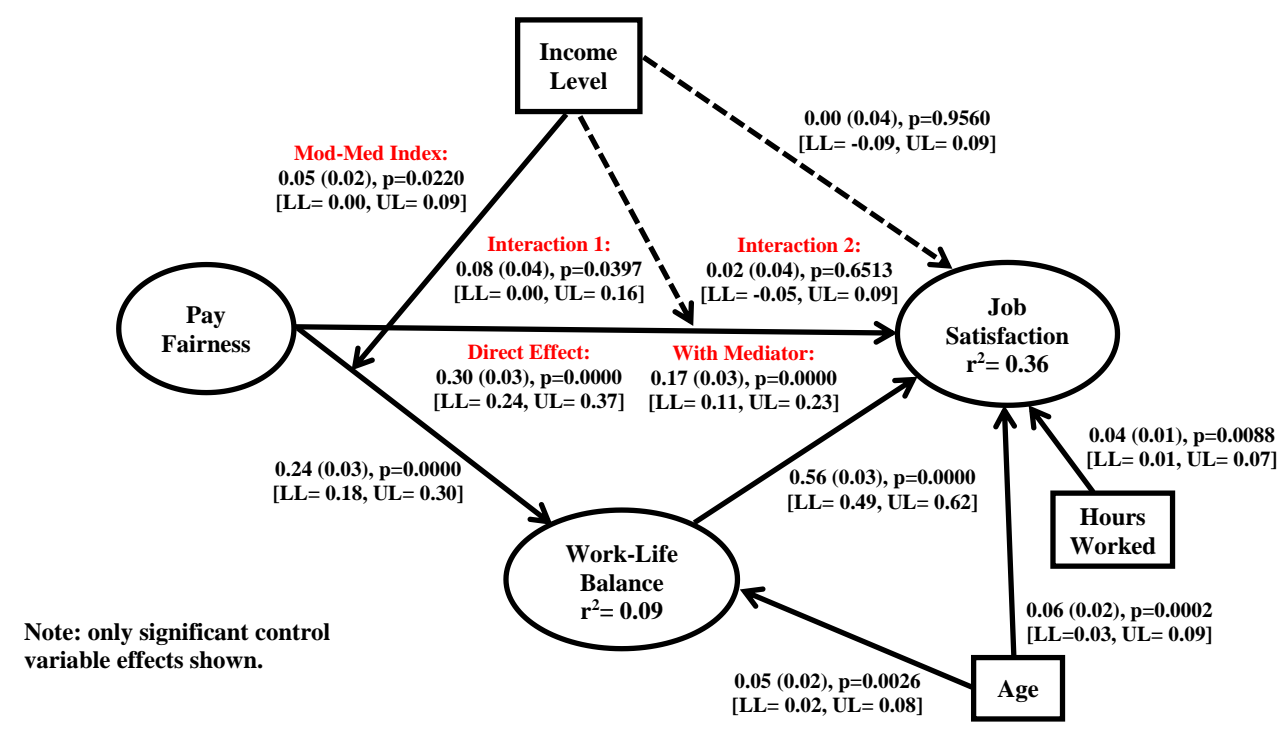

Figure 2. Model of Analyses.

The results show that pay fairness is significantly related to both work-life balance $(\beta=0.24$ $(0.03), p=0.0000[\mathrm{LL}=0.18, \mathrm{UL}=0.30])$ and job satisfaction $(\beta=0.30(0.03), p=0.0000[\mathrm{LL}=0.24$, $\mathrm{UL}=0.37])$, supporting hypotheses 1 and 2 . Furthermore, work-life balance is significantly related to job satisfaction $(\beta=0.56(0.03), p=0.0000[\mathrm{LL}=0.49, \mathrm{UL}=0.62])$, and when included in the model, it partially mediates the effect of pay fairness on job satisfaction: $(\beta=0.17(0.03), p=0.0000$ $[\mathrm{LL}=0.11, \mathrm{UL}=0.23])$. These findings support Hypothesis 3 . Hypothesis 4 related to income level moderating effects, and this was supported for Hypothesis $4 \mathrm{a}$, with a significant two-way interaction between pay fairness and income level toward work-life balance ( $\beta=0.08(0.04), p=0.0397$ [LL $=0.00$, $\mathrm{UL}=0.16])$. However, Hypothesis $4 \mathrm{~b}$ was not supported, with a non-significant two-way interaction being found between pay fairness and income level toward job satisfaction $(\beta=0.02(0.04), p=0.6513$ $[\mathrm{LL}=-0.05, \mathrm{UL}=0.09])$. The results of the index of moderated mediation was found to be significant (Index $=0.05(0.02), p=0.0220[\mathrm{LL}=0.00, \mathrm{UL}=0.09]$ ), supporting Hypothesis 5. Hayes [35] asserted that the interpretation of this effect means that the indirect effect of work-life balance on job satisfaction (which partially mediating the effects of pay fairness) differs between respondents with different income levels. We present the graphed interactions to illustrate effects in Figures 3 and 4.

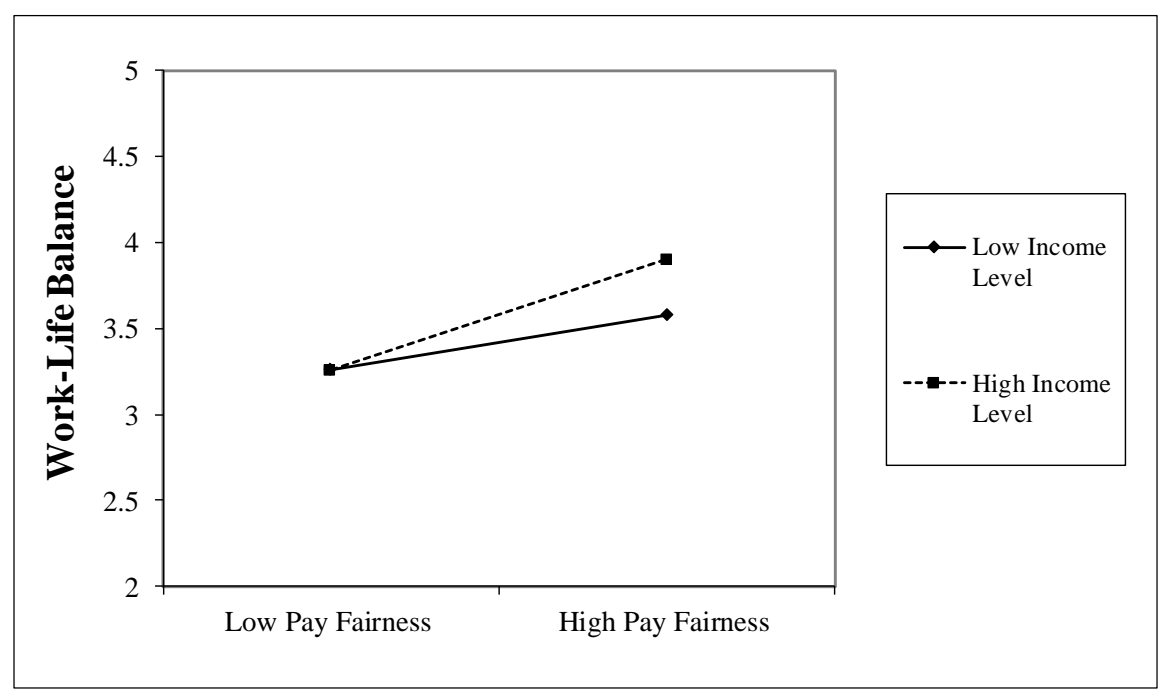

Figure 3. Interaction Effects of Income Level on Pay Fairness with Work-Life Balance as the Dependent Variable. 


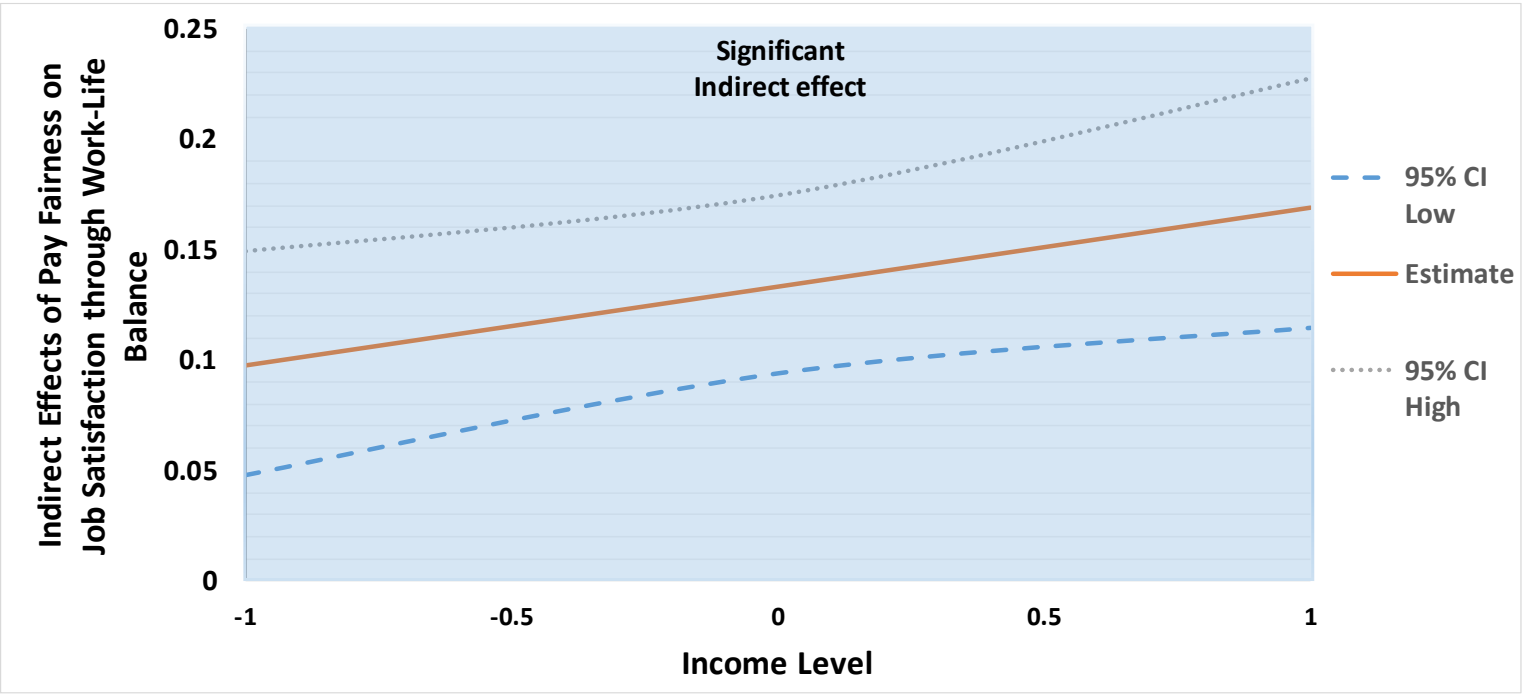

Figure 4. Indirect Effects of Pay Fairness on Job Satisfaction through Work-Life Balance Conditional on Income Level.

Figure 3 shows that at low levels of pay fairness, the influence on work-life balance is not significantly different for respondents across the three income levels. However, there are significant differences amongst respondents at high levels of pay fairness. Respondents with high income levels and high pay fairness report significantly higher work-life balance than those with low income levels. This effect supports our Hypothesis 4a, because income level does positively influence the effect of pay fairness on work-life balance. Regarding Hypothesis 5 (moderated mediation effect), we follow the approach of Wayne et al. [46] to probe the conditional indirect effect by examining the magnitude and significance of the indirect effect of pay fairness on job satisfaction through work-life balance at the three levels of income. Figure 4 shows the significant indirect effect of pay fairness-work-life balance-job satisfaction, which is conditional on the effects of income level (at -1 SD, mean, and +1 $\mathrm{SD}$ ). We find that for respondents with low income (up to $\$ 20,000$ per annum), the effect of pay fairness on job satisfaction vis-à-vis work-life balance was positive but small (estimate $=0.10, p=0.0001$; LLCI $=0.05$; ULCI $=0.15$ ). For those with mean income (roughly the $\$ 20,001-40,000$ per annum), the effect of pay fairness on job satisfaction vis-à-vis work-life balance was also positive, but slightly larger (estimate $=0.13, p=0.0000 ; \mathrm{LLCI}=0.09 ; \mathrm{ULCI}=0.17$ ). Finally, for respondents in the high-income group (roughly $\$ 40,001-60,000$ per annum), the effect of pay fairness on job satisfaction vis-à-vis work-life balance was positive, and the largest (estimate $=0.17, p=0.0000 ; \mathrm{LLCI}=0.12$; ULCI $=0.23$ ). This indicates that higher income levels are associated with a stronger positive indirect effect from pay fairness to job satisfaction through work-life balance. The indirect effect is significant across all levels of income, although its effect is strengthened as income levels increase, supporting Hypothesis 5.

\section{Discussion}

The present study explored the influence of pay fairness toward work-life balance and job satisfaction amongst a sample of working poor and median income earners, and found broad support for the literature around the importance of organizational justice perceptions around pay influencing job satisfaction [21,22]. Importantly, it also provides new insights into the work-life balance literature, by finding that pay fairness is also an antecedent to work-life balance, extending the findings of Judge and Collquitt [26] around organizational justice and work-family conflict. The strength of our findings show pay fairness has a moderate influence on work-life balance and job satisfaction amongst this sample of working poor. Thus, the perceptions of employees around their pay in relation to those above them in their organization-immediate supervisor, managers, and the CEO-influences the ability of workers to manage their work and non-work roles, as well as shaping their satisfaction with their 
work. Given that the links to job satisfaction align with meta-analytic findings, for example Colquitt et al. and Cohen-Charash and Spector [21,22], this supports organizational justice as a universally important factor, at least across employees of various income levels.

In addition to direct effects, we also found that work-life balance partially mediated the influence of pay fairness on job satisfaction, and this effect was confirmed with bootstrapping analysis. Thus, while the links between work-life balance and job satisfaction have been determined, for example Haar et al. and Haar $[13,23]$, we find that balancing work and non-work roles can only partially reduce the influence of pay fairness on job satisfaction. This finding also highlights that work-life balance is not only a middle-class or higher-earner phenomenon, but rather an issue that is universally important for all employees, including the working poor. This might highlight that for the working poor, pay fairness is ever constant and at the forefront of their awareness, as it might be a fundamental issue for working poor. Again though, this finding does reiterate the importance of work-life balance in understanding the influence of organizational just theories on job satisfaction and builds off the findings of Judge and Colquitt [26]. Future studies involving organizational justice might want to consider the role that work-life balance plays.

While income level correlated significantly with job satisfaction-replicating the meta-analytic findings of Judge et al. [4] — these effects were smaller in comparison to the meta-analysis findings: $r=0.17$ [4] versus $r=0.08$ (present study). Furthermore, this effect became non-significant in our model, indicating that pay fairness and work-life balance are likely more important influences of job satisfaction than income level itself. We suggest this might be due to the overall condition of work and pay for the working poor. Further exploration of these aspects is warranted.

Beyond the mediation effects, we contribute significantly to the literature by testing income level as a moderator on the influence of pay fairness. If pay fairness and thus organizational justice is a true universally important factor, we might expect its influence to be consistent and not tempered by the level of income earned by an employee. However, few studies have tested organizational justice theories at such low levels of employee income. We found no significant moderating effect between pay fairness and job satisfaction across income levels, providing some support for this relationship as being universal, at least across low-income employees. We did find a significant effect toward work-life balance, with respondents with higher income reporting higher work-life balance at high levels of pay fairness. This might represent that work-life balance is reliant on a certain level of income. At the low-income level (up to $\$ 20,000$ ), employees might simply be scrambling to live, and thus, their survival mode makes balancing work and non-work poorer. In effect, they have little money to spend on 'life activities' beyond food and rent. Higher paid employees $(\$ 40,001-60,000)$ includes the median income of New Zealand, and thus represents a modest level of income, but one that provides some opportunities for activities beyond rent and food, and thus the likely more positive influence on work-life balance when pay fairness is high.

Importantly, we also found support for moderated mediation effects that highlighted that pay fairness might work better-has a stronger influence-for higher income levels, regarding the work-life balance mediating the effect on job satisfaction. This provides support for conditional process modeling [35], which enabled us to determine the boundary conditions of the indirect effects of income level on the mediation effect of work-life balance. Our results supported a boundary condition, whereby income level plays a key moderating effect on the mediated relationship of pay fairness through work-life balance and ultimately job satisfaction. The effects of the moderated mediation show that work-life balance is universally beneficial to job satisfaction (as a mediator), although this is under a boundary condition of income level: as income level increases, the influence of work-life balance becomes stronger. The findings support a boundary condition [46] whereby the mediating effect is affected by income level. It shows that the importance of work-life balance becomes stronger as income level increases, aligning with the two-way moderation effect argument presented above. It is likely that having greater income- even up to the median income level—provides greater opportunities for activities beyond basic existence, which then increases the importance of work-life balance. 


\subsection{Implications and Future Research}

There is growing attention that employee well-being is at risk form work-related factors [7], and that the psychology of sustainability [6,8] provides a useful avenue for better examining and addressing these factors. The present study focused on job satisfaction, and aligned with the principles of the psychology of sustainability [6,8], we focused on the working poor to better understand the way the well-being of low-paid workers is shaped by income. Clearly, an implication for employers is to address substantive, procedural, and relative pay fairness specifically for the worker (e.g., a living wage) but also, as shown in the context of the present study, in relation to others within an organization. Larger firms that pay CEOs exorbitant income packages may alienate workers and lower their fairness perceptions, which in turn will reduce their well-being. This also is important for the 'bottom line', given the links between job satisfaction and job performance [11]. The findings here show that income level can play an additional influence, so employers looking to rectify their potential 'bad jobs' [30,31] by paying more and providing greater access and work security are likely to enhance the well-being of workers (and their performance), and play a stronger role in creating a sustainable workforce for the future $[6,8]$.

There are also strong implications for policy. Despite economic arguments and resistance to raising minimum income levels, the evidence here clearly shows that those on the lowest income groups (here \$0-20,000) are in many ways worse off. Perhaps setting minimum income levels higher would enable these employees to gain a better grasp of their work and life roles, and enjoy a higher work-life balance, which has implications for psychological well-being $[13,23]$. Importantly, this income boost would likely enhance job satisfaction and ultimately influence job performance [11]. Addressing minimum income standards would also address the United Nations (UN) Sustainable Development Goals [47], especially Goal 1 relating to the eradication of poverty-in our context, the working poor-and the development of policy that is sensitive to the poor. In addition, our findings align with Goal 8 around decent work, Goal 3 around good health and well-being, and Goal 10 around reducing inequalities. Thus, we suggest there is much to be gained in meeting these UN Development Goals through raising income levels amongst the lowest paid in New Zealand. This does align with the current New Zealand Government's commitment to Fair Pay Agreements [48], whereby sector-level bargaining arrangements enable unions and employers to set minimum terms and conditions for all of the workers across an industry or occupation.

The findings also provide direction for researchers. We encourage researchers to explore moderated mediation with income levels to gain stronger insights into relationships. Importantly, the lack of significant effects might provide some indication of more universal relationships, so we also encourage the reporting of non-significant effects to clarify theories that might operate evenly across low and modest-income earning workers. That said, more studies examining the working poor might also highlight the challenges that such workers face. Researchers could also examine alternative outcomes, including organizational commitment or turnover intentions, with the latter having meta-analytic support for a small effect from pay [5]. Replicating these effects toward turnover intentions and/or performance might also provide useful insights that encourage employers to ultimately pay better.

\subsection{Limitations}

Podsakoff et al. [49] noted the potential for common method variance (CMV) through self-reported survey data, and the present study uses cross-sectional data, making this a potential limitation. However, this approach is typical of the literature, for example, see the meta-analysis (2010). Some researchers [13] have recommended the use of SEM, and specifically the CFA tests, to provide an initial robust test that can highlight potential CMV issues. In this regard, Haar et al. [13] suggested that determining the factor structure of constructs and the poorer fit of alternative CFAs (where constructs are combined) provides an indication of no $\mathrm{CMV}$, because we would expect alternative CFAs to be potentially better if CMV existed. Furthermore, the use of PROCESS has been found to be as robust 
as SEM [50]. In addition, Monte Carlo analysis [51] showed that significant moderating effects are much less likely if CMV is an issue. Furthermore, we confirmed the work-life balance mediating effects through bootstrapping, which provides enhanced empirical confidence on the mediating effects. Beyond the statistical analysis conducted, our sample of over 850 New Zealand lower paid and working poor across a broad range of factors, including sector and industry, occupations, and firm size, providing enhanced generalizability compared to studies that have focused on a single firm, or only one industry. However, we do acknowledge that the data was a paid panel, and this may create some issues around data quality [52], although we suggest this is a necessity given the sample we sought. Furthermore, concern might be raised that since the surveys are online (computer or smartphone), there is the potential for some respondents to be excluded. However, Qualtrics does have a large pool of respondents to draw on-including the working poor-but we acknowledge that our sample might potentially be less representative of the entire population.

\section{Conclusions}

Overall, the present study provides insights into the process by how pay fairness amongst the working poor can influence employee well-being (job satisfaction), specifically through the process by which work-life balance mediates this relationship. Importantly, we find a complex set of relationships with the mediating influence of work-life balance being strongest in high income levels, with a weaker mediation effect for low paid employees. Importantly, our findings highlight work-life balance as an important factor for all employees-including the working poor-and might represent a stepping stone toward achieving higher wellbeing. As employees rise above in their income spectrum, the influence of work-life balance becomes stronger, signaling that work-life balance might be a 'stepping stone' to achieving greater well-being. These findings highlight the advantage of studies exploring boundary condition, and we encourage researchers to explore additional relationships from low-paid workers in order to understand the universality (or not) of theories on such under-represented employee groups. Ultimately, as we seek to build more psychologically sustainable workplaces, we believe researchers must consider the role of income and the effects that it has on employees earning much less than the typical focus of employee studies, which are often white-collared professionals.

Author Contributions: Conceptualization, J.H. and S.C.C.; Data curation, J.H.; Formal analysis, J.H.; Funding acquisition, J.H., S.C.C., J.P., J.A., D.H. and S.A.-T.; Project administration, S.C.C.; Writing-original draft, J.H.; Writing-review \& editing, S.C.C., J.A.

Funding: This research was funded by the Royal Society of New Zealand, grant number [17-MAU-137].

Conflicts of Interest: The authors declare no conflict of interest.

\section{References}

1. Bergman, M.E.; Jean, V.A. Where have all the "workers" gone? A critical analysis of the unrepresentativeness of our samples relative to the labour market in the Industrial-Organizational Psychology literature. Ind. Organ. Psychol. 2015, 9, 84-113. [CrossRef]

2. Carr, S.C.; Parker, J.; Arrowsmith, J.; Haar, J.; Jones, H. Humanistic Management and Living Wages: A Case of Compelling Connections? Hum. Manag. J. 2017, 1, 215-236. [CrossRef]

3. Gloss, A.; Carr, S.C.; Reichman, W.; Abdul-Nasiru, I. From Handmaidens to POSH Humanitarians. Ind. Organ. Psychol. J. 2016, 10, 1-41.

4. Judge, T.A.; Piccolo, R.F.; Podsakoff, N.P.; Shaw, J.C.; Rich, B.L. The relationship between pay and job satisfaction: A meta-analysis of the literature. J. Vocat. Behav. 2010, 77, 157-167. [CrossRef]

5. Griffeth, R.W.; Hom, P.W.; Gaertner, S. A meta-analysis of antecedents and correlates of employee turnover: Update, moderator tests, and research implications for the next millennium. J. Manag. 2000, 26, 463-488. [CrossRef]

6. Di Fabio, A. The psychology of sustainability and sustainable development for well-being in organizations. Front. Psychol. 2017, 8, 1534. [CrossRef] [PubMed] 
7. Di Fabio, A.; Kenny, M.E. From decent work to decent lives: Positive self and relational management (PS\&RM) in the twenty-first century. Front. Psychol. 2016, 7, 361. [CrossRef] [PubMed]

8. Di Fabio, A. Positive healthy organizations: Promoting well-being, meaningfulness, and sustainability in organizations. Front. Psychol. 2017, 8, 1938. [CrossRef] [PubMed]

9. Greenberg, J. A taxonomy of organizational justice theories. Acad. Manag. Rev. 1987, 12, 9-22. [CrossRef]

10. Haar, J.M.; Spell, C.S. How does distributive justice affect work attitudes? The moderating effects of autonomy. Int. J. Hum. Resour. Manag. 2009, 20, 1827-1842. [CrossRef]

11. Judge, T.A.; Thoresen, C.J.; Bono, J.E.; Patton, G.K. The job satisfaction-job performance relationship: A qualitative and quantitative review. Psychol. Bull. 2001, 127, 376-407. [CrossRef] [PubMed]

12. Haar, J.; Roche, M.; Brougham, D. Indigenous Insights into Ethical Leadership: A Study of Māori Leaders. J. Bus. Ethics 2018, 1-20. [CrossRef]

13. Haar, J.M.; Russo, M.; Sune, A.; Ollier-Malaterre, A. Outcomes of work-life balance on job satisfaction, life satisfaction and mental health: A study across seven cultures. J. Vocat. Behav. 2014, 85, 361-373. [CrossRef]

14. Cropanzano, R.; Bowen, D.E.; Gilliland, S.W. The management of organizational justice. Acad. Manag. Perspect. 2007, 21, 34-48. [CrossRef]

15. Rupp, D.E.; Shapiro, D.L.; Folger, R.; Skarlicki, D.P.; Shao, R. A critical analysis of the conceptualization and measurement of organizational justice: Is it time for reassessment? Acad. Manag. Ann. 2017, 11, 919-959. [CrossRef]

16. Carr, S.C.; Maleka, M.; Meyer, I.; Barry, M.L.; Haar, J.; Parker, J.; Arrowsmith, J.; Yao, C.; Hodgetts, D.; Jones, H.; et al. How can wages sustain a living? By getting ahead of the curve. Sustain. Sci. 2018, 13, 901-917. [CrossRef]

17. Adams, J.S. Inequity in social exchange. In Advances in Experimental Social Psychology; Berkowitz, L., Ed.; Academic Press: New York, NY, USA, 1965; Volume 2, pp. 267-299.

18. Lind, E.A.; Tyler, T.R. The Social Psychology of Procedural Justice; Plenum Press: New York, NY, USA, 1988.

19. Bies, R.J.; Moag, J.S. Interactional justice: Communication criteria of fairness. In Research on Negotiation in Organizations; Rlewicki, J., Sheppard, B.H., Bazerman, M.H., Eds.; JAI Press: Greenwich, CT, USA, 1986; Volume 1, pp. 43-55.

20. Masterson, S.S.; Lewis, K.; Goldman, B.M.; Taylor, M.S. Integrating justice and social exchange: The differing effects of fair procedures and treatment of work relationships. Acad. Manag. J. 2000, 43, 738-748.

21. Colquitt, J.A.; Conlon, D.E.; Wesson, M.J.; Porter, C.O.L.H.; Ng, K.Y. Justice at the Millennium: A meta-analytic review of 25 years of organizational justice research. J. Appl. Psychol. 2001, 86, 425-445. [CrossRef] [PubMed]

22. Cohen-Charash, Y.; Spector, P.E. The role of justice in organizations: A meta-analysis. Organ. Behav. Hum. Decis. Process. 2001, 86, 278-321. [CrossRef]

23. Haar, J.M. Testing a new measure of work-life balance: A study of parent and non-parent employees from New Zealand. Int. J. Hum. Resour. Manag. 2013, 24, 3305-3324. [CrossRef]

24. Russo, M.; Shteigman, A.; Carmeli, A. Workplace and family support and work-life balance: Implications for individual psychological availability and energy at work. J. Posit. Psychol. 2016, 11, 173-188. [CrossRef]

25. Haar, J.M.; Sune, A.; Russo, M.; Ollier-Malaterre, A. A cross-national study on the antecedents of work-life balance from the fit and balance perspective. Soc. Indic. Res. 2018, 1-22. [CrossRef]

26. Judge, T.A.; Colquitt, J.A. Organizational justice and stress: The mediating role of work-family conflict. J. Appl. Psychol. 2004, 89, 394-404. [CrossRef] [PubMed]

27. Haar, J.; Brougham, D.; Roche, M.A.; Barney, A. Servant leadership and work engagement: The mediating role of work-life balance. N. Z. J. Hum. Resour. Manag. 2017, 17, 56-72.

28. Brough, P.; Timms, C.; O’Driscoll, M.P.; Kalliath, T.; Siu, O.L.; Sit, C.; Lo, D. Work-life balance: A longitudinal evaluation of a new measure across Australia and New Zealand workers. Int. J. Hum. Resour. Manag. 2014, 25, 2724-2744. [CrossRef]

29. Carr, S.C.; Parker, J.; Arrowsmith, J.; Watters, P.A.; Jones, H. Anti-poverty living wages: Evidence from New Zealand. Labour Ind. 2016, 26, 24-39. [CrossRef]

30. Kim, M. The working poor: Lousy jobs or lazy workers? J. Econ. Issues 1998, 32, 65-78. [CrossRef]

31. Kalleberg, A.L.; Reskin, B.F.; Hudson, K. Bad jobs in America: Standard and nonstandard employment relations and job quality in the United States. Am. Sociol. Rev. 2000, 65, 256-278. [CrossRef] 
32. McGovern, P.; Smeaton, D.; Hill, S. Bad jobs in Britain: Nonstandard employment and job quality. Work. Occup. 2004, 31, 225-249. [CrossRef]

33. Williams, M.L.; McDaniel, M.A.; Nguyen, N.T. A meta-analysis of the antecedents and consequences of pay level satisfaction. J. Appl. Psychol. 2006, 91, 392-413. [CrossRef] [PubMed]

34. Hayes, A.F. Introduction to Mediation, Moderation, and Conditional Process Analysis: A Regression-Based Perspective, 2nd ed.; The Guilford Press: New York, NY, USA, 2018.

35. Hayes, A.F. Partial, conditional, and moderated moderated mediation: Quantification, inference, and interpretation. Commun. Monogr. 2017, 1-37. [CrossRef]

36. Statistics New Zealand Labour Market Statistics (Income): June 2017 Quarter. Statistics New Zealand: Wellington, New Zealand, 2017. Available online: https:/ / www.stats.govt.nz/information-releases/labourmarket-statistics-income-june-2017-quarter (accessed on 10 November 2018).

37. Kaplan, D.M.; Berkley, R.A.; Fisher, J.E. Applicant identity congruence in selection decision making: Implications for Alejandro and Consuela. Hum. Resour. Manag. 2016, 55, 39-51. [CrossRef]

38. Vitell, S.J.; King, R.A.; Howie, K.; Toti, J.F.; Albert, L.; Hidalgo, E.R.; Yacout, O. Spirituality, moral identity, and consumer ethics: A multi-cultural study. J. Bus. Ethics 2016, 139, 147-160. [CrossRef]

39. Ferguson, J.L.; Ellen, P.S.; Bearden, W.O. Procedural and distributive fairness: Determinants of overall price fairness. J. Bus. Ethics 2014, 121, 217-231. [CrossRef]

40. Haar, J.M.; Roche, M.; ten Brummelhuis, L. A daily diary study of work-life balance in managers: Utilizing a daily process model. Int. J. Hum. Resour. Manag. 2017, 1-23. [CrossRef]

41. Judge, T.A.; Bono, J.E.; Erez, A.; Locke, E.A. Core self-evaluations and job and life satisfaction: The role of self-concordance and goal attainment. J. Appl. Psychol. 2005, 90, 257-268. [CrossRef] [PubMed]

42. Ng, T.W.; Feldman, D.C. Long work hours: A social identity perspective on meta-analysis data. J. Organ. Behav. 2008, 29, 853-880. [CrossRef]

43. Ng, T.W.; Feldman, D.C. The relationships of age with job attitudes: A meta-analysis. Pers. Psychol. 2010, 63, 677-718. [CrossRef]

44. Williams, L.J.; Vandenberg, R.J.; Edwards, J.R. Structural equation modelling in management research: A guide for improved analysis. Acad. Manag. Ann. 2009, 3, 543-604. [CrossRef]

45. Hair, J.F.; Black, W.C.; Babin, B.J.; Anderson, R.E. Multivariate Data Analysis: A Global Perspective, 7th ed.; Pearson Prentice Hall Publishing: Upper Saddle River, NJ, USA, 2010.

46. Wayne, S.J.; Lemmon, G.; Hoobler, J.M.; Cheung, G.W.; Wilson, M.S. The ripple effect: A spillover model of the detrimental impact of work-family conflict on job success. J. Organ. Behav. 2017, 38, 876-894. [CrossRef]

47. United Nations. Transforming Our World: The 2030 Agenda for Sustainable Development. 2016. Available online: https:/ / sustainabledevelopment.un.org/post2015/transformingourworld (accessed on 28 October 2018).

48. Ministry of Business, Innovation and Employment. Fair Pay Agreements. Available online: https:// www.mbie.govt.nz/info-services/employment-skills/legislation-reviews/fair-pay-agreements (accessed on 31 October 2018).

49. Podsakoff, P.M.; MacKenzie, S.B.; Lee, J.Y.; Podsakoff, N.P. Common method biases in behavioral research: A critical review of the literature and recommended remedies. J. Appl. Psychol. 2003, 88, 879-903. [CrossRef] [PubMed]

50. Hayes, A.F.; Montoya, A.K.; Rockwood, N.J. The analysis of mechanisms and their contingencies: PROCESS versus structural equation modeling. Australas. Mark. J. 2017, 25, 76-81. [CrossRef]

51. Evans, M. A Monte Carlo study of the effects of correlated method variance in moderated multiple regression analysis. Organ. Behav. Hum. Decis. Process. 1985, 36, 305-323. [CrossRef]

52. Yang, S.; Zhao, Y.; Dhar, R. Modeling the underreporting bias in panel survey data. Mark. Sci. 2010, 29, 525-539. [CrossRef]

(C) 2018 by the authors. Licensee MDPI, Basel, Switzerland. This article is an open access article distributed under the terms and conditions of the Creative Commons Attribution (CC BY) license (http:/ / creativecommons.org/licenses/by/4.0/). 